\title{
Civicae
}

Abr a Set $2020-v .2-$ n.2

ISSN: 2674-6646

This article is also available online at: www.cognitionis.inf.br

\section{Educação para jovens e adultos integrada à educação do campo}

A educação para jovens e adultos (EJA) e a educação do campo são partes integrantes e no processo histórico educacional do Brasil, mediante a importância dessas modalidades de ensino esse trabalho tem como objetivo principal discutir a relevância social da EJA no processo de inserção de políticas pública voltada para a educação do campo. A metodologia utilizada foi uma pesquisa bibliográfica, abordando vários conceitos e ideias sobre os temas. Conclui-se que essa integração da EJA com educação do campo possibilita maiores intervenções nas comunidades por meio das políticas públicas e consequentemente contribui para a melhoria da qualidade de vida dos sujeitos e diminuição do êxodo rural.

Palavras-chave: EJA; Educação do campo; Políticas públicas; Êxodo rural.

\section{Education for young people and adults in the rural education}

Education for youth and adults (EJA) and rural education are integral parts and in the historical educational process of Brazil, due to the importance of these teaching modalities, this work has as main objective to discuss the social relevance of EJA in the process of inserting policies public education for rural education. The methodology used was a bibliographic search, addressing various concepts and ideas on the themes. It is concluded that this integration of EJA with rura education enables greater interventions in communities through public policies and consequently contributes to improving the quality of life of the subjects and reducing the rural exodus.

Keywords: EJA; Rural education; Public policy; Rural exodus.

\section{Topic: Andragogia (Educação de Adultos)}

Reviewed anonymously in the process of blind peer.
Received: 05/04/2020

Approved: 19/07/2020

Almires Martins Freitas

Instituto Federal Baiano, Brasil

http://lattes.cnpq.br/3365862542382229

http://orcid.org/0000-0003-2590-7138

irismartins240@gmail.com

Yane Gama da Silva (iD

Instituto Federal Baiano, Brasil

http://lattes.cnpq.br/6287071164744153

http://orcid.org/0000-0001-7905-5036

yanegama21@gmail.com

Ilma da Silva Cabral in

Instituto Federal Baiano, Brasil

http://lattes.cnpq.br/5371764530531969

http://orcid.org/0000-0002-1317-3088

ilma.cabral@ifbaiano.edu.br

\section{Referencing this:}

FREITAS, A. M.; SILVA, Y. G.; CABRAL, I. S.. Educação para jovens e adultos integrada à educação do campo. Justitia Liber, v.2, n.2, p.2329, 2020. DOI: http://doi.org/10.6008/CBPC2674-6646.2020.002.0005 


\section{INTRODUÇÃO}

A educação do campo e a educação para jovens e adultos (EJA) são partes integrantes e fundamentais no processo histórico educacional do Brasil, mediante a importância dessas duas vertentes são necessárias cada vez mais alternativas para alcançarem os indivíduos pertencentes a essas classes, que foram excluídos durante muito tempo pela sociedade, por razões étnicas, sociais entre outras.

Nesse contexto, esse trabalho tem como objetivo principal discutir a relevância social da EJA no processo de inserção de políticas pública voltada para a educação do campo, evidenciando a necessidade dessas políticas para ampliação da educação do campo e salientando a importância de compreender a EJA como ponto fundamental para a melhoria da qualidade de vida dos indivíduos e diminuição do êxodo rural. Nessa perspectiva a EJA é uma importante modalidade de ensino e tem papel fundamental no processo de formação básica do cidadão como está descrito na Lei de Diretrizes e bases da educação nacional (LDB), Lei $n^{\circ}$ 9.394/1996.

Diante disso, utilizamos como base de estudo pesquisa bibliográfica sobre as áreas da educação do campo e da escolarização de jovens e adultos analisando as intervenções com políticas publica que são desenvolvidas. Foram coletados dados do livro Desenvolvimento Sustentável e Solidário com Enfoque Territorial: caderno pedagógico educandas e educandos, produzido pelo ministério da educação, neste estão contidas informações referentes à luta da população rural por melhores condições de vida. Também utilizamos como objeto de estudo alguns autores como: Silva, Pizzani, Nascimento, Guido, Arroyo, Caldart, Molina, Hamburgo, Gomes e dados da LDB lei $n^{\circ}$ 9.394/1996 que relata a importância da EJA enquanto modalidade de ensino. Os subtítulos desse trabalho foram divididos em quatro partes, inicialmente com foco conceitual da EJA e da educação do campo enquanto modalidades de ensino, a segunda parte relata a integração da EJA na inserção de políticas públicas voltadas para a educação do campo, a terceira traz o tema juventude(s) do campo em movimento com dados informativos contidos no livro Desenvolvimento Sustentável e Solidário com Enfoque Territorial e a quarta parte tange a EJA como ponto fundamental para a melhoria da qualidade de vida dos sujeitos e diminuição do êxodo rural.

\section{METODOLOGIA}

A metodologia adotada foi uma pesquisa bibliográfica, sendo esta abordagem uma revisão da literatura sobre as principais teorias que norteiam o trabalho científico. Essa revisão é o que chamamos de levantamento bibliográfico ou revisão bibliográfica, a qual pode ser realizada em livros, periódicos, artigo de jornais, sites da Internet entre outras fontes (PIZZANI et al., 2012).

Dessa forma, dividimos o trabalho por fases, iniciando com a escolha do tema e organização dos objetivos, posteriormente buscamos referências bibliográficas apropriadas para melhor relatar os assuntos e por fim utilizamos de técnicas como resumos e fichamentos de textos para seleção de autores e aprimoramento de ideias para escrita desse artigo. 


\section{DISCUSSÃO TEÓRICA}

\section{Conceitos da EJA e educação do campo enquanto modalidade de ensino}

A educação de jovens e adultos (EJA) é uma modalidade específica do ensino fundamental e ensino médio, destinada aos sujeitos do campo e da cidade, a qual possibilita aos mesmos o acesso ao conhecimento que foi negado ao longo de suas vidas, dando a oportunidade de jovens ou adultos iniciar ou dar continuidade aos estudos.

O motivo pelo qual essas pessoas deixam os estudos ou até mesmo nem iniciam estão ligados a vários fatores, como condições socioeconômicas falta de vagas sistema de ensino adequado e outros. Conforme Nascimento (2003) existe diversos fatores que muitas vezes não possibilitam a alfabetização no período da infância no decorrer dos anos, o indivíduo sente a necessidade de inserir-se nesse processo e procura a EJA (Educação de Jovens e Adultos) oferecido por escolas públicas.

De acordo com a Lei de Diretrizes e bases da educação nacional (LDB), lei n 9.394/1996, em seu Artigo 37, deixa claro que a educação de jovens e adultos será destinada aqueles que não tiveram acesso ou continuidade de estudos no ensino fundamental e médio na idade própria (BRASIL, 1996). Com base com na LDB 9394/96 (art. 32), as exigências do ensino na educação de jovens e adultos (EJA), o ensino fundamental deverá ter por objetivo a formação básica do cidadão, mediante:

I. O desenvolvimento da capacidade de aprender, tendo como meios básicos o pleno domínio da leitura, da escrita e do cálculo;

II. A compreensão do ambiente natural e social, do sistema político, da tecnologia, das artes e dos valores em que se fundamenta a sociedade; III. O desenvolvimento da capacidade de aprendizagem, tendo em vista à aquisição de conhecimentos e habilidades e a formação de atitudes e valores; IV. O fortalecimento dos vínculos de família, dos laços de solidariedade humana e de tolerância recíproca em que se assenta a vida social.

O ensino médio, conforme a LDB, tem como finalidades:

I. A consolidação e o aprofundamento dos conhecimentos adquiridos no ensino fundamental, possibilitando o prosseguimento de estudos;

II. A preparação básica para o trabalho e a cidadania do educando, para continuar aprendendo, de modo a ser capaz de se adaptar com flexibilidade a novas condições de ocupação ou aperfeiçoamento posteriores;

III. O aprimoramento do educando como pessoa humana, incluindo a formação ética e o desenvolvimento da autonomia intelectual e do pensamento crítico; e prática. (BRASIL, 1996)

Conforme Guido (2007), o mesmo ressalta que quando se insiste na questão da Educação e Cidadania, é porque a sociedade ainda carece desses fatores vitais, portanto, assim o mesmo confirma a ausência da verdadeira educação e da autêntica cidadania. Ao considerarmos, em particular, o espaço rural, essa carência se torna ainda mais evidente. Com isso surgiu a necessidade da Educação no campo, que se trata de uma política pública que possibilita o acesso ao direito à educação das pessoas que vivem fora do meio urbano e que necessitam ter esse direito garantido da mesma forma que é assegurado para as pessoas da população urbana.

A Resolução no 4783/2010 em seu Art. 3o, prescreve que “As Escolas do Campo são aquelas inseridas em comunidades caracterizadas pelo vínculo e trabalho com a terra, independentemente de sua localização". 
Já a promulgação da Lei de Diretrizes e Bases da Educação 9394/96 (LDB) de 20 de dezembro de 1996, diz que a educação do campo é entendida como àquela que ocorre nas instituições escolares situadas na área rural.

Para Morigi (2003), a Educação do Campo deve ser aquela que assume a identidade do meio rural, comprometida com um projeto político pedagógico voltado às causas, desafios, sonhos, história e cultura daquele que vive e atua no campo. Portanto, é importante que a educação no campo se coloque na luta pelos direitos: direito ao saber, ao conhecimento, à cultura produzida socialmente. Arroyo et al. (2004) consideram a educação como direito do homem, da mulher, da criança e do jovem do campo.

Sendo assim, entendemos que a escola é o espaço de formação social e política dos sujeitos, ao mesmo tempo, que está possui como função social a socialização dos saberes acumulados e os processos de reelaboração e produção dos conhecimentos pelos homens ao longo dos tempos. Portanto, para àqueles que vivem no campo, é também um espaço de luta e resistência.

\section{EJA: inserção de políticas públicas voltadas para a educação do campo}

A Educação de jovens e adultos (EJA) e a Educação do Campo são campos difusores de experiências e que alavancam o conhecimento em muitas áreas, perfazendo um fazer pedagógico de suma importância para a construção e/ou afirmação do pertencimento dos indivíduos ruralistas em seu meio. A Educação de Jovens e Adultos é destinada à população do campo é uma educação transformadora. Esta modalidade iniciase pela garantia do direito à educação e segue na afirmação de um modelo de educação. Por isso, que as experiências escolares da EJA Campo são tão intensas. Elas representam a própria experiência da vida, da luta e do desejo de uma aprendizagem para além da transmissão do conhecimento da ciência e da técnica. (ALENCAR, 2010).

De acordo Silva (2000), o processo histórico da educação do campo e da EJA é marcado por um processo excludente dessas classes, pois a escolarização brasileira, de 1500 até o início do século XX, serviu para atender as elites, sendo inacessível para grande parte da população rural. Assim, seguindo o histórico educacional da EJA e educação do campo é a partir dos anos 30 do século XX que começa a delinear-se um modelo de educação rural amarrado a projetos de "modernização do campo", patrocinado por organismos de "cooperação" norte-americana e difundido através do sistema de assistência técnica e extensão rural (CALAZANS, 1993).

Segundo Ferrari (1991), as políticas públicas para a escolarização das populações rurais mostram seu fraco desempenho ou o desinteresse do Estado com respeito à educação rural, quando analisamos o analfabetismo no Brasil que, ainda em 1991, continuava a ser mais elevado na área rural do que na área urbana. Nessa perspectiva, vale ressaltar que as pessoas do campo "historicamente era alvo de preconceitos, e era vista como 'gente atrasada' e 'rude'", sempre foram consideradas sem cultura, sem educação e, pior, como se servissem apenas para trabalhar no campo, e que, portanto, não precisariam de uma educação formal. E para ilustrar destaca-se "o personagem 'Jeca Tatu', criado por Monteiro Lobato para indicar o caipira da região rural de São Paulo relegado pelo Estado, foi inculcado no imaginário social brasileiro para 
se referir ao sujeito do campo como 'miserável', 'pobre' e 'desleixado'” (LOCKS et al., 2015).

Com isso se deu a necessidade de diferenciar educação rural e do campo, em que ambas se referem ao direito à educação à população do campo, mas com perspectivas diferentes, pois surgem em épocas históricas distintas. A educação rural predominou até a segunda metade do século XX, em que não havia uma preocupação com a cultura e costumes do homem do campo. Rosa et al. (2008) abordam que "A educação rural era predominantemente vista como algo que atendia a uma classe da população que vivia num atraso tecnológico, subordinado, a serviço da população dos centros urbanos". Isso significa dizer que a educação voltada para as pessoas do campo era fora da realidade na qual a escola estava inserida.

Com relação à educação do campo, verifica-se que essa começa a se intensificar a partir da segunda metade do século $X X$, através de reivindicações de movimentos sociais e da sociedade civil, que desejavam uma educação voltada para os interesses e necessidades da população do campo, bem como uma educação que valorizasse a cultura e a identidade dessa população. Percebe-se que com tais movimentos havia o desejo de uma educação inclusiva e autônoma (TRAVESSINI, 2015). A educação do campo, nesse caminho, se apresenta como uma bandeira de luta dos movimentos sociais do campo pelo direito à educação das populações campesinas; sendo de suma importância o surgimento e efetivação de políticas públicas que auxiliem as vertentes da educação do campo e da EJA.

\section{Juventude(s) do campo em movimento}

Diante dos fundamentos mencionados anteriormente a respeito do contexto histórico da EJA, educação do campo e suas relações, este subcapitulo traz dados informativos contidos no livro Desenvolvimento Sustentável e Solidário com Enfoque Territorial: caderno pedagógico educandas e educandos, produzido pelo ministério da educação. Nesse, são relatados os incontestáveis avanços das políticas públicas no Brasil, muitas experiências e vem sendo implementadas, os movimentos sociais, entidades e governos têm assumido responsabilidades na ampliação de políticas para jovens do campo e cidade.

A primeira Conferência Nacional de Juventude realizada no Brasil em 2008 promoveu a deliberação de prioridades das bandeiras da juventude por políticas públicas. Assim, as juventudes do campo foram reconhecidas no seu direito a educação. A partir dessa primeira Conferência Nacional deliberou-se a criação de uma política nacional de juventude e meio ambiente, qualificação da juventude nas áreas ambientais, utilizando recursos como Fundo de Amparo ao trabalhador - FAT, entre outros, para atuarem em projetos de educação ambiental, unidades de conservação, ecoturismo, recuperação das áreas degradadas entre outras.

A obra relata que com a formação de coletivos, a juventude rural implementa alternativas para fixar o jovem no campo. Em 2004 foi iniciada a formação dos coletivos municipais de jovens, onde a juventude teve a oportunidade de expor as necessidades de suas comunidades. Enfatiza que a falta de alternativas para geração de trabalho e renda provocam o afastamento do jovem de seu território. De tal modo, é evidente a importância das políticas públicas no contexto de afirmação do pertencimento local, e de geração de oportunidades para melhoria de vida de jovens e adultos. 
Baseado nos coletivos surgiu o Programa de Políticas Públicas do MOC (Territórios rurais com jovens), que através das capacitações realizadas os jovens aprendem processos educativos voltados para a realidade do semiárido, observando temáticas relacionadas sobre a cidadania, políticas públicas e geração de renda na agricultura familiar. O livro apresenta ainda várias histórias de experiências de jovens que mudaram de vida por meio de políticas públicas implantadas em suas regiões, pois as mesmas enfatizam o fortalecimento da cultura e saberes locais, buscando firmar o a diminuição do êxodo rural por falta de alternativas para esses indivíduos.

Outro ponto em destaque é o programa Jovem Saber, que consiste na formação de jovens a partir de três eixos de estudo: formação profissional, política sindical e política pública, no qual são trabalhados temas como desenvolvimento sustentável, educação do campo, agroecologia, organização da produção e social, sendo esses uma das ações político-pedagógicas desenvolvida pela CONTAG.

\section{EJA como ponto fundamental para a melhoria da qualidade de vida dos sujeitos e diminuição do êxodo} rural.

Com base nos estudos bibliográficos feitos analisamos que os sujeitos que retomam seus estudos e procuram depois de algum tempo são na maioria pessoas de classe trabalhadora, vivendo de subemprego ou desempregados e procuram a escola coma aspiração de para melhores possibilidades de emprego, sendo a EJA uma oportunidade para isso. A Educação de Jovens e Adultos tem como intenção primordial a reparação de uma dívida social. Assim, ela torna-se um momento de nova significação de vida para os indivíduos que irão refletir acerca dos seus conhecimentos, e ampliá-los de forma a atender as suas necessidades pessoais (GOMES, 2015).

Vale confirmar que a EJA é uma educação admissível, capaz de transformar significativamente a vida de um indivíduo, permitindo uma nova história de vida e permite as pessoas não só um momento a ser preenchido, mas um significativo processo formativo. A declaração de Hamburgo (BRASIL, 2004) nos diz que:

A educação de adultos engloba todo o processo de aprendizagem, formal ou informal, onde pessoas consideradas "adultas" pela sociedade desenvolvem suas habilidades, enriquecem seu conhecimento e aperfeiçoam suas qualificações técnicas e profissionais, direcionandoas para a satisfação de suas necessidades e as de sua sociedade.

Com isso, a Educação de Jovens e Adultos permite aos alunos novas oportunidades, devolve aos mesmos o estudo formal, pois esses já possuem um saber próprio resultantes de experiências desenvolvidas ao longo da vida, pelo fato de dedicarem-se muito cedo a uma atividade produtiva, assim como a Educação de jovens e adultos cumpre somente um processo escolar como atende as necessidades os indivíduos envolvidos, tornando a EJA um requisito indispensável para o acesso ao conhecimento e inserção de mulheres e homens, jovens e adultos nos processos sociais.

Dessa forma, a inserção de políticas públicas que apoiem a bandeira da EJA é de suma importância, pois essas desencadeiam uma série de benefícios para os indivíduos envolvidos tanto pessoais como profissional, visto que, contribuem para a melhoria da qualidade de vida geral dos mesmos e consequentemente diminuição do êxodo rural, já que essas políticas articulam atividades que são 
desenvolvidas na própria comunidade dando suporte para permanência dos participantes no seu local de origem.

\section{CONCLUSÕES}

Com base nas pesquisas desenvolvidas foi possível analisar a relevância social da EJA no processo de inserção de políticas pública voltada para a educação do campo, evidenciando a mesma como um instrumento capaz de transformar a vida de todos os envolvidos. Desse modo, sendo a EJA uma importante modalidade de ensino conforme a LDB, esta articula o emprego das políticas pública para a difusão de conhecimentos e oportunidades para os sujeitos participantes sendo fundamental para sua permanência e subsistência no seu local de origem.

Diante disso, essa discussão da relevância social da EJA no processo de inserção de políticas pública voltada para a educação do campo possibilita uma ampliação da educação do campo e da EJA como ambientes educacionais. Assim, consideramos que essa integração da EJA com educação do campo favorece e possibilita maiores intervenções nas comunidades por meio das políticas pública e consequentemente contribui para a melhoria da qualidade de vida dos sujeitos e diminuição do êxodo rural.

\section{REFERÊNCIAS}

ARROYO, M. G.; CALDART, R. S.; MOLINA, M. C.. Por uma educação do campo. Petrópolis: Vozes, 2004.

ALENCAR, M. F. S.. Educação do campo e a formação de professores: Construção de uma política educacional para o campo brasileiro. Ci. \& Tróp., Recife, v.34, n.2, p.207226, 2010.

BRASIL. Decreto n. 2.208, de 17 de abril de 1997. Regulamenta o parágrafo 20 do art. 36 e os artigos 39 e 42 da Lei $n$. 9394, de 20 de dezembro de 1996, que estabelece as diretrizes e bases da educação nacional. Brasília: DOU, 1997.

BRASIL. Legislação Informatizada. Lei n. 9.394, de 20 de dezembro de 1996. Brasília: DOU, 1996.

BRASIL. Ministério da Educação. UNESCO. Declaração de Hamburgo sobre Educação de Adultos: VCONFINTEA. Brasília: MEC, 2004.

CALAZANS, M. J. C.. Para compreender a educação do Estado no Meio Rural: traços de uma trajetória. In: THERRIEN, J.; DAMASCENO, M. N.. Educação e escola no campo. Campinas: Papirus, 1993. p.15-40.

GOMES, A. C.. Os significados que os alunos da EJA têm em relação à instituição escolar. Dissertação (Mestrado) Universidade do Estado da Bahia, Salvador, 2015.
GUIDO, H.. Filosofia da Educação: entre o anti-moderno e o ultra-moderno. In: HENZ, C. I.; ROSSATO, R.. Educação humanizadora na sociedade globalizada. Santa Maria: Biblos, 2007.

LOCKS, G. A.; GRAUPE, M. E.; PEREIRA, J. A.. Educação do Campo e direitos humanos: uma conquista, muitos desafios. UCS, 2015.

MORIGI, V.. A escola do MST: uma utopia em construção. Porto Alegre: Mediação, 2003.

PIZZANI, L.; SILVA, R. C.; BELLO, S. F.; HAYASHI, M. C. P. I.. A arte da pesquisa bibliográfica na busca do conhecimento. Rev. Dig. Bibl. Ci. Inf., Campinas, v.10, n.1, p.5366, 2012.

ROSA, D. S.; CAETANO, M. R.. Da educação rural à educação do campo: uma trajetória, seus desafios e suas perspectivas. Portal trilhas, 2008.

SILVA, M. S.. Os saberes do professorado rural: Construídos na vida, na lida e na formação. Dissertação (Mestrado) Universidade Federal de Pernambuco, Recife, 2000.

TRAVESSINI, D. M.. Educação do Campo ou Educação Rural? Os conceitos e a prática a partir de São Miguel do Iguaçu, PR. Monografia (Bacharelado em Desenvolvimento Rural e Segurança Alimentar) - Universidade Federal da Integração Latino-Americana, Foz do Iguaçu, 2015.

A CBPC - Companhia Brasileira de Produção Científica (CNPJ: 11.221.422/0001-03) detém os direitos materiais desta publicação. Os direitos referem-se à publicação do trabalho em qualquer parte do mundo, incluindo os direitos às renovaç̃̃es, expansões e disseminações da contribuição, bem como outros direitos subsidiários. Todos os trabalhos publicados eletronicamente poderão posteriormente ser publicados em coletâneas impressas sob coordenação da Cognitionis Publishing, da Companhia Brasileira de Produção Científica e seus parceiros autorizados. Os (as) autores (as) preservam os direitos autorais, mas não têm permissão para a publicação da contribuição em outro meio, impresso ou digital, em português ou em tradução. 